\title{
When Psychiatric Diseases Speak Skin: About 78 Patients in a Medical Caravan
}

\section{Aqil N*, Baybay H, Oulehri A, Gallouj S, Rammouz I and Mernissi FZ \\ Dermatology, University Hospital Center Hassan II, Fez, Morroco}

*Corresponding author: Niema Aqil, Centre hospitalier universitaire Hassan II, Fès, Maroc, Tel: 00212661328727; Email: niemaaqil90@gmail.com

\section{Research Article}

Volume 3 Issue 3

Received Date: October 26, 2018

Published Date: November 08, 2018

DOI: $10.23880 /$ cdoaj-16000159

\section{Abstract}

Introduction: Dermatologists often face a psychiatric comorbidity of their patients. The question is: is this association bidirectional?

Materials and method: The study concerned patients hospitalized in the department of psychiatry of Hassan II CHU of Fez during a medical caravan. All patients were examined by two dermatologists.

Results: Of 78 hospitalized patients, we recorded 51 cases of dermatosis disease. The average age was 36.4 years old. Sex ratio F/M: 1,04. 41\% of the patients consumed toxic substances. Psychiatric diseases were psychosis (67\%) dominated by schizophrenia. The neurosis represented (33\%) with a predominance of the major depressive disorder. Six groups of dermatoses were distinguished: hygiene-related dermatosis dominated by infectious disease (51\%), skin diseases aggravated by mental disorders (29.4\%), psychic disorders secondary to dermatosis (25.5\%), psychic disorders responsible for skin disorders (15.7\%) and cases of association with no apparent relation (9.8\%). Only one case of urticaria induced by drug consumption was noted. Some dermatoses were listed in two groups simultaneously.

Discussion: The collaboration between the psychiatrist and the dermatologist is essential given the presence of links between the skin and the psyche and the resulting clinical implication, in order to improve the overall care for both types of pathologies.

Keywords: Psychiatric; Dermatosis; Disease; Medical caravan, University Hospital Center Hassan II Fez

\section{Introduction}

Psychocutaneous disease, defined as primary psychiatric disease with skin manifestations, is commonly encountered in dermatology. Dermatologists can play an important role in the management of psychocutaneous disease because patients visit dermatology for treatment of their skin problems but often refuse psychiatric intervention [1]. The question is: is this association bidirectional? That is, each of these two dermatological or psychiatric diseases would have a potential effect on the appearance of the other. To answer this question, we conducted this study. 


\section{Patients and Methods}

The study concerned patients hospitalized in the psychiatric department of the University Hospital Center Hassan II of Fez Morocco during a medical caravan. All the participants were diagnosed and confirmed cases of psychiatric diseases. Each patient was examined by two dermatologists. Socio-demographic data was collected. Patients suffering from the skin disease were included in study. Patients refusing consent for interview and suffering from severe medical illness were excluded. Data collection and analysis was done on computer software (SPSS version 17.0). Data thus collected was subjected to statistical analysis for the fulfillment of aims and objectives.

\section{Results}

Of 78 hospitalized patients, we recorded 51 cases of dermatosis disease, i.e. $65.4 \%$ of patients. The average age was 36.4 years old. Sex ratio F/M: $1,04.41 \%$ of the patients consumed toxic substances. Psychiatric diseases were psychosis (67\%) dominated by schizophrenia. The neurosis represented $(33 \%)$ with a predominance of the major depressive disorder (Figure 1). Six groups of dermatoses were distinguished: hygiene-related dermatosis dominated by infectious disease (51\%), skin diseases aggravated by mental disorders $(29.4 \%)$, psychic disorders secondary to dermatosis (25.5\%), psychic disorders responsible for skin disorders (15.7\%) and cases of association with no apparent relation (9.8\%). Only one case of urticaria induced by drug consumption was noted. Some dermatoses were listed in two groups simultaneously (Figure 2).

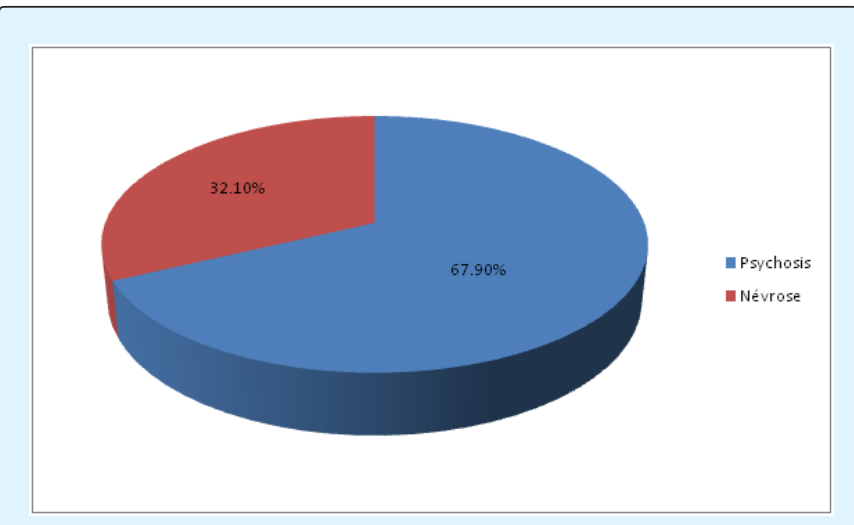

Figure 1: Distribution of psychiatric diseases.

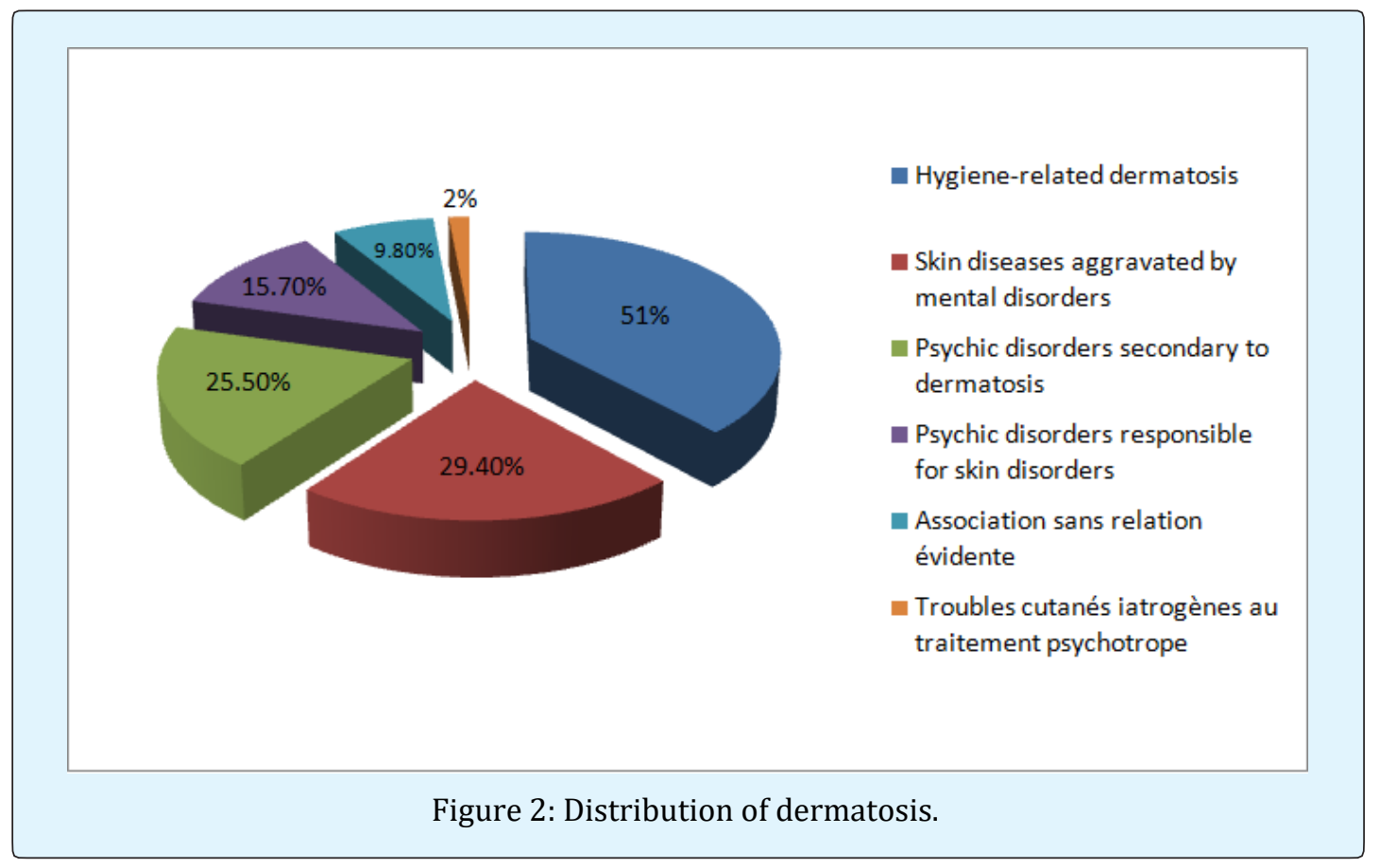

The number of female psychiatric patients was 28/78; 26 of them had skin diseases, $77 \%$ of them had psychosis. Infectious skin diseases affected $59 \%$ of the 26 patients.
The number of male psychiatric patients was 50/78; 25 of them had skin diseases, $56 \%$ of them had psychosis. 


\section{Clinical Dermatology Open Access Journal}

Infectious skin diseases affected $41 \%$ of the 46 patients (Table 1).

\begin{tabular}{|c|c|c|c|c|c|c|}
\hline \multirow{2}{*}{ Sex of patients } & \multicolumn{2}{|c|}{ Psychosis } & \multicolumn{2}{|c|}{ Neurosis } & \multicolumn{2}{|c|}{$\begin{array}{c}\text { Infectious skin } \\
\text { diseases }\end{array}$} \\
\cline { 2 - 7 } & No. & $\%$ & No. & $\%$ & No. & $\%$ \\
\hline Female (26) & 20 & 77 & 6 & 23 & 16 & 59 \\
\hline Male (25) & 14 & 56 & 11 & 44 & 11 & 41 \\
\hline Total (No.) & \multicolumn{3}{|c|}{34} & \multicolumn{2}{|c|}{17} & \multicolumn{2}{|c|}{27} \\
\hline
\end{tabular}

Table 1: Prevalence of sex in the type of psychiatric illness and secondary infectious dermatosis.

The analytical results found that hygiene-related dermatosis are more common in patients using toxic substances and having psychosis $(\mathrm{p}<0.05)$. (Table 2 and 3) Dermatosis secondary to psychic disorders such as dermatitis artefacta was more common in psychosis ( $p$ $<0.05$ ). (Table 4) This analysis also found a significant association between neurosis and dermatosis responsible of psychological disorders such as psoriasis (Table 4).

\begin{tabular}{|c|c|c|c|c|c|c|}
\hline \multirow{2}{*}{$\begin{array}{c}\text { Skin disease } \\
\text { Type of } \\
\text { psychiatric } \\
\text { illness }\end{array}$} & \multicolumn{2}{|c|}{ Infectious } & \multicolumn{2}{|c|}{$\begin{array}{c}\text { Non } \\
\text { Infectious }\end{array}$} & \multirow{2}{*}{$\begin{array}{l}\text { Total } \\
\text { (No.) }\end{array}$} & \multirow{2}{*}{$\begin{array}{c}P \\
\text { value }\end{array}$} \\
\hline & & $\%$ & o. & $\%$ & & \\
\hline Psychosis & & 65 & & 5 & 34 & \multirow{2}{*}{$<0,05$} \\
\hline Neurosis & 5 & 29 & 12 & 71 & 17 & \\
\hline
\end{tabular}

Table 2: Frequency of infectious versus non-infectious skin diseases in relation to type of psychiatric illness.

\begin{tabular}{|c|c|c|c|c|c|c|}
\hline \multirow{2}{*}{$\begin{array}{c}\text { Skin disease } \\
\text { Drug } \\
\text { consumption }\end{array}$} & \multicolumn{2}{|c|}{ Infectious } & \multicolumn{2}{|c|}{ Non Infectious } & \multirow{2}{*}{$\begin{array}{l}\text { Total } \\
\text { (No.) }\end{array}$} & \multirow{2}{*}{$\begin{array}{c}P \\
\text { value }\end{array}$} \\
\hline & No. & $\%$ & No. & $\%$ & & \\
\hline Yes & 20 & 95 & 1 & 5 & 21 & \\
\hline No & 7 & 23 & 23 & 77 & 30 & \\
\hline
\end{tabular}

Table 3: Frequency of infectious versus non-infectious skin diseases in relation to drug consumption.

\begin{tabular}{|c|c|c|c|c|c|c|}
\hline \multirow{2}{*}{$\begin{array}{c}\text { Type of psychiatric } \\
\text { illness } \\
\text { Skin disease }\end{array}$} & \multicolumn{2}{|c|}{ Psychosis } & \multicolumn{2}{|c|}{ Neurosis } & \multirow{2}{*}{$\begin{array}{l}\text { Total } \\
\text { (No.) }\end{array}$} & \multirow{2}{*}{$\begin{array}{l}P \\
P\end{array}$} \\
\hline & No. & 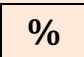 & No. & 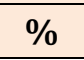 & & \\
\hline & 7 & 87,5 & 1 & 12,5 & 8 & \\
\hline $\begin{array}{l}\text { Dermatosis responsible } \\
\text { of psychological } \\
\text { disorders }\end{array}$ & 4 & 31 & 9 & 69 & 13 & \\
\hline
\end{tabular}

Table 4: Prevalence of some skin diseases according to the psychiatric disorder.

\section{Discussion}

Our study confirms the interest of a joint consultation involving a psychiatrist and a dermatologist given the large number and variability of dermatosis found. In the present study, a clear positive relation was detected between psychiatric disorders and the presence of skin diseases, as skin diseases were detected in $65.4 \%$ of psychiatric patients. This is in agreement with Mookhoek, et al. [2] who found that skin diseases were more common in psychiatric patients (77\%). This collaboration has four types of indication: dermatosis influenced by psychological factors, psychological or psychiatric disorders secondary to a dermatosis, psychiatric disorders with cutaneous expression and dermatosis related to a lack of hygiene. The profile of these dermatosis varies according to the psychiatric pathology so we note that the prevalence of hygiene dermatosis in the group of psychotic patients is highly significant, which could be explained by the lack of interest of these patients in their cleanliness, favored by drug use. Segerstrom and Miller [3] reported that psychiatric disorders and chronic stress in adults are consistently associated with decreased natural killer (NK) cell cytotoxicity and decreased lymphocyte proliferation leading to increased susceptibility to infectious skin diseases. The most common types of infectious skin diseases in psychiatric patients in the current study was parasitic infestations, followed by fungal, then bacterial, and lastly viral infections. - The high prevalence of skin infections in schizophrenic patients may be due to negligence of hygiene [4]. Schizophrenic patients were unable to carry out their normal daily activities or were unable to work, in addition to a poor level of personal awareness regarding personal hygiene and overall cleanliness [5]. In the current study, it was found that the prevalence of infectious skin diseases was higher in patients who consume drugs, with significant difference. This may be attributed to smoking, alcohol and drug abuse, thereby leading to decreased immunity and increasing the susceptibility to infections. Alcohol has been shown to suppress selected functions of the immune system, therefore compromising host defenses against bacterial infections. It has an adverse effect on killer cells, which are important in the body's defense system, and suppresses the B cells, which form antibodies [6].

Also the psychological factors have an important place in the triggering and / or the evolution of the dermatosis found in $45 \%$ of our series. In the group of neurosis, there was a significant relationship with the group of dermatosis responsible for psychological disorders, based 


\section{Clinical Dermatology Open Access Journal}

on the vulnerability of these patients to their dermatological diseases, sometimes pronounced.

\section{Conclusion}

The collaboration between the psychiatrist and the dermatologist is essential given the association between psychiatric disease and skin disease sounds bidirectional. Infectious skin diseases are the most common skin disease categories in psychiatric patients. Although psychogenic skin disorders occur exclusively in primary psychiatric disorder patients, it is much less frequent than the infectious skin diseases overall. Accordingly, it is recommended that health education with a focus on special hygiene measures be made available to psychiatric patients and their caregivers for prevention and control of infections. Periodic monthly inspections of psychiatric patients should be carried out for early detection of any infectious skin diseases [7].

\section{Ethics Approval and Consent to Participate:}

The study has been approved by the ethics committee of faculty of medicine of fez.

An informed consent to participate in the study was obtained from the patient.

\section{Consent for Publication}

Written informed consent was obtained from the patients for publication of this study and any accompanying images. A copy of the written consent is available for review by the Editor-in-Chief of this journal.

\section{Authors' Contribution}

All the authors contributed for the interpretation of data for the work; and drafting the work or revising it critically for important intellectual content; and the final approval of the version to be published; and the agreement to be accountable for all aspects of the work in ensuring that questions related to the accuracy or integrity of any part of the work are appropriately investigated and resolved.

\section{References}

1. Kuhn H, Mennella C, Magid M, Stamu-O'Brien C, Kroumpouzos G (2017) Psychocutaneous disease: Clinical perspectives. J Am Acad Dermatol 76(5): 779791.

2. Mookhoek EJ, Van De Kerkhof PC, Hovens JE, Brouwers JR, Loonen AJ (2010) Skin disorders in chronic psychiatric illness. J Eur Acad Dermatol Venereol 24(10): 1151-1156.

3. Segerstrom SC, Miller GE (2004) Psychological stress and the human immune system: a meta-analytic study of 30 years of inquiry. Psychol Bull 130(4): 601-630.

4. Mercan S, Kivac Altunay I (2006) Psychodermatology: collaboration between psychiatry and dermatology. Turk Psikiyatri Derq 17(4): 305-313.

5. David N, Oshawa ON (2005) Schizophrenia daily news blog: the toll of brain disorders.

6. Nelson S, Bagby GJ, Bainton BG, Summer WR (1989) The effects of acute and chronic alcoholism on tumor necrosis factor and the inflammatory response. J Infect Dis 160(3): 422-429.

7. Moftah NH, Kamel AM, Attia HM, El-Baz MZ, Abd ElMoty HM (2013) Skin diseases in patients with primary psychiatric conditions: A hospital based study. J Epidemiol Glob Health 3(3): 131-138. 